velopment, which has recently seen the implementation of a new batch retrospectiveconversion subsystem, and added COM catalog options and online authority verification during input/edit.

While not the only bibliographic system to be successfully replicated, the WLN Computer System is becoming the most systematically replicated main-frame facility, with a broad range of future possibilities, including that of a truly turnkey system. WLN's experience indicates that, if a system is designed for ease of maintenance at perhaps some sacrifice of efficiency, it will be readily transportable and allow others to obtain the benefits of a highly sophisticated bibliographic capability without the everincreasing cost of original development and, more importantly, without having to support the ongoing maintenance of a unique system.

\section{A General Planning Methodology for Automation}

Richard W. MEYER, Beth Ann REULAND, Francisco M. DIAZ, and Frances COLBURN: Clemson University, Clemson, South Carolina.

\section{INTRODUCTION}

A workable planning methodology is the logical starting place for the successful implementation of automation in libraries. An automation plan may develop on the basis of an informal arrangement or from the efforts of one individual, but just as often, automation plans are developed by committees. An automation planning committee must determine and execute some kind of planning methodology and is more likely to be successful if it starts with clear guidelines, good leadership, and a thoroughly proven approach.

As a summary review of the literature will bear out, many libraries have developed their own planning techniques inhouse. Some of these, which are addressed to the issues of cataloging rule changes and public-access catalogs, have been very well thought out. ${ }^{1}$ However, these techniques are generally not directed to planning for library-wide automation, and are usually designed to meet the specific needs of an individual library. Although the pattern for these studies is often similar, they do not seem to be based upon any general automation design methodology. Neither, in addition, does there seem to be a general methodology available through any external library agency. The Office of Library Management Studies of the Association of Research Libraries has developed a number of programs designed to assist libraries with their planning efforts, some of which appear to be useful in automation development. ${ }^{2}$ But for many libraries, these programs may be too broad, too time-consuming or too expensive. As an alternative, some libraries will need to look elsewhere for a general automation planning methodology. This problem was addressed by the administration of the Clemson library, and was resolved in a unique way.

\section{BACKGROUND}

The Robert Muldrow Cooper Library of Clemson University has the responsibility of acquiring, preserving, and making available for use the many materials needed by faculty and students in their research and instructional efforts. At a typical landgrant institution like Clemson, the amount of scholarly publishing and the pressure to develop research proposals has risen sharply in recent years. The increased needs of users working with an expanding and diversified collection have resulted in a doubling of circulation activity, and have required the growth of library staff by 70 percent over the last decade. Furthermore, acquisition, processing, and access problems are compounded by the high inflation rate of materials, particularly serial publications, and manpower costs.

Even though user demands heavily burdened the traditional manual systems, the extent of library automation at Clemson had been limited to a batch circulation system, a simple serials-listing capability, and the use of bibliographic utilities. Although it had been generally accepted for some time that the acquisitions and fund-control functions at Clemson were in need of automation, no concrete approach to develop- 
ing a system had been established. In addition, there was some concern that the development of an automated acquisitions system shouldn't be initiated without a clear understanding of how such an effort would affect the rest of the functions in the library. With this in mind, and as an initial part of planning, the library administration decided to implement a programmed study to determine specific needs and problems of the whole library at Clemson and to determine the attendant costs and benefits of their resolution. Since developing the methodology for this kind of study effort inhouse has been shown by experience elsewhere to be both expensive and time-consuming, a planning methodology was sought which could be brought in from outside the library and applied in a timely fashion. The International Business Machines Corporation (IBM), through their local marketing representative, volunteered to supply that methodology by means of an Education Industry Application Transfer Team (ATT) study. In order to implement the study, a team was organized consisting of representatives from the library, from the university's Division of Administrative Programming Services (DAPS), and from the IBM Corporation. The purpose, approach, and results of that study constitute the rest of this paper.

\section{PURPOSE}

The Application Transfer Team methodology was implemented to fulfill a fourfold purpose.

- First, it was necessary to act on the recognized need for a library-wide automation plan with something tangible that library and university administrators could use in the decision-making process.

- Second, basic objectives and implementation estimates were required to provide groundwork to the development of systems specifications and evaluation.

- Third, the planning process needed to provide a forum for meaningful participation by a number of library staff and users.

- Fourth, the planning needed to be accomplished rather quickly.

The ATT met all these requirements. Although the ATT study technique is generalized for work on any problem in the educa- tion arena, it seems particularly well suited to the library environment because it is oriented toward developing applications that solve production problems.

The Application Transfer Team methodology was developed by the IBM Corporation for customer use. The ATT methodology evolved from IBM's Business System Planning Function, which has been operational since the early 1970s. Although the methodology has been used several times in the academic environment, this is the first time, to our knowledge, that it has been used in a library operation. The strength of the ATT is that it helps members of a team with diverse backgrounds to understand the environment under study. Its final goal was "to improve operational productivity, provide better service to students, and provide information which can enhance management planning and decision making." 3 Put to work, the methodology is straightforward and effective. From beginning to end, the ATT process took Clemson slightly more than three months elapsed time. Total work time (including all report writing) for library staff was approximately one thousand man hours.

As the initial step with the ATT methodology, it was necessary to engage a sponsor and to select a team. For this study, the sponsor chosen was the dean of graduate studies, who reported directly to the vicepresident for academic affairs. In turn, the director of computing and the director of the Division of Administrative Programming Services (DAPS) reported to the dean of graduate studies. Although it was not critical that the sponsor be intimately involved in the project, his level of authority within the university administration would help to secure acceptance of the study's recommendation. The sponsor also provided cogent advice along the way, based upon his understanding of institutional resources, and he served as a communication link with other university administrative offices.

The study team was chosen by the library administration with the intention of getting diverse involvement and expertise. Library staff included the associate director, the head of circulation, the serials cataloger, and a reference librarian. Although only the associate director brought significant 
experience in library automation development, the head of circulation contributed substantial practical experience with automation systems. The cataloger offered specifics of bibliographic problems, cataloging rule changes, and serials control issues, and the reference librarian contributed a comprehensive knowledge of informationretrieval concerns.

Outside staff included the director of DAPS, who furnished details on the Clemson computing environment, and an IBM marketing representative, who provided appropriate help with hardware capabilities, the ATT methodology, and legwork. In addition, Clemson was also able to engage the help of a representative of IBM's Education Industry Division to guide the ATT efforts on the basis of his experience in the use of the methodology. From time to time, other IBM and DAPS staff were involved in assisting with interviews and report writing. The associate director served as team chair in order to act as spokesperson, to coordinate team effort, and to edit the final report.

\section{METHODOLOGY}

The Application Transfer Team methodology is applied in six phases. IBM recommends that these phases be conducted sequentially, and that they last from five to sixteen weeks, depending on the size of the problem. Throughout the process, verbal reviews were conducted by the team with the sponsor and with the library staff.

The first phase involved an organizational session. Following the introduction of team members, the IBM Education Industry Division representative presented an overview of the methodology and explained the mechanics of the ATT study process. The team then established the scope of the study by choosing an application area on which to focus and by determining the general objectives of the final system to be implemented. Since part of the purpose of the project was to develop a plan for librarywide automation, it was quickly recognized by the team that the application area should be an integrated library information system. However, the IBM representative suggested that this scope was too broad for the study and that one functional area such as acquisitions be chosen, with other functions reserved for subsequent ATT studies. Given time constraints, a compromise arrangement was made in which serials control was determined as the scope. Since serials control is a single functional area, but encompasses nearly all bibliographic issues, it served as a microcosm of overall library operations. Therefore, it was generally accepted that a plan that effectively accommodated serials would constitute an integrated system plan. The organizational phase continued by determining who to interview during the data-collections phase and by setting up an interview schedule. This phase was concluded by developing an outline of the final report and by assigning writing responsibilities to individual team members.

The data-gathering effort constituted phase two. This involved structured interviews of representative staff of each unit of the library who were involved in routine interactions with any phase of serials control at Clemson. Interviews were conducted with staff from acquisitions, cataloging, circulation, reference units, and branch libraries as well as the university business office, students, and faculty.

Following an outline in the ATT, each person interviewed was asked for specific details of his work with serial publications regarding (1) interfaces (or points of interaction), (2) concerns or needs, (3) suggested improvements, (4) expected values or benefits of improvements, (5) work volume, and (6) cycles. Data gathered in each of these interview sessions were immediately documented in a letter to the interviewees. These letters were reviewed by those interviewed for corrections and added detail.

Data from completed and documented interviews were consolidated during the third phase of the study into a matrix of each of the six questions plotted against operational areas of the library, graphically designating areas of the greatest concern to the largest part of the library. This composite was analyzed to separate problems that could be reasonably handled by an integrated automation system from those that needed the attention of administrative policy and direction. Functions for automation consideration were then examined in a 
"blue sky" session of the committee to envision what system would accommodate the specifications for serials control and access that each library unit and serials user required. From this session a synthesis emerged of the architecture for an integrated system. ${ }^{4}$ This architecture included a description of the basic relationships of functional modules of the system, a list of the various files needed to contain system information, and a list of data elements required for bibliographic holdings, acquisition, and patron records in the system database.

Phase four called for the translation of the architecture and general system requirements into modules on basic access, acquisition or processing functions, and into the individual programs needed to execute each module. The team divided into two parts. The IBM and DAPS personnel, with the associate director, listed the modules and programs and formulated descriptions of each. Part of the description effort involved drafting approximate flowcharts of each program. Using algorithms developed by IBM, these descriptions were used to assign estimates of person hours required to create the necessary modules. In order to determine the overall cost of system development the person-hour figures were converted to dollars using an average hourly cost for Clemson DAPS personnel.

Committee members not involved in program/module design formed a group to evaluate anticipated benefits defined in the interviews, to collect data from library staff to support these expectations, and to assign a value to them. Benefits from reduced file maintenance, processing, and tracking time were valued as person hours saved by the new system. Additional improvements were projected for the system's capability for better fund control, more complete and immediate on-order, claiming, and inprocess information, and statistical collection development/use data. These benefits were assigned the value of estimated duplicate and inappropriate material acquired under the present system. A value was not assigned to user benefits. Faculty and student satisfaction is intangible, and variable from case to case. Enhanced user service was recognized as a substantial benefit of the proposed system, but was not quantified. The cost factors determined in phase four were consolidated with derived benefit values to form a cost/benefit analysis, which constituted phase five.

In the sixth and final phase an implementation plan was formulated. This plan, along with recommended target dates, was presented orally to library staff and university administration. In addition, the entire process, recommendations, and plan of action were documented in a written report. ${ }^{5}$

\section{RESULTS}

Within the ATT report were a description of the current library environment, objectives and description of the proposed system, implementation considerations, a cost/benefits analysis, and recommendations for a plan of action. Although care was taken to "walk through" the function of each module of the described system, the report was not intended to provide detailed computer program specifications ready to be coded by a programmer. It described a useful and powerful integrated serials system in sufficient detail to be a working tool in the hands of a knowledgeable systems analyst to match (or revise) already available systems and programs to the library's specifications. The report itself also served as an effective communication link with the university administration, setting out library concerns and giving rational solutions to the pervasive problem of serials control and, in the long term, to an integrated library information system.

The timing of the ATT study was fortunate for the Clemson library. The university was on the eve of an accreditation selfstudy. As often happens with the examination of any organization, a host of related, but unacknowledged, problems surfaced in the course of the ATT study. During the interviews, staff members felt free to bring up matters of unclear policies, misunderstood hierarchical arrangements, and staffing inadequacies throughout the library. The number and importance of non- 
automation concerns was significant enough that an administrative report was written to articulate these problems to the university administration. ${ }^{6}$ It is interesting to note also that, while in every instance the team received enthusiastic cooperation from all those interviewed, there was fear among some staff members that any automation project would necessarily cut staff positions. Once this worry was identified, the study team was able to allay those fears by explaining the study's purpose.

One of the greatest contributions of the ATT study has been the direction it has given the library for future goals and priorities. By focusing on the problems of serials control, the team evaluated a microcosm of library problems. Investigating these problems in the environment of more limited budgets, possible future closing or freezing of the card catalog, and increased user demands for services has helped the library develop a course of action, a resolve of mission, and a direction for future growth.

The staff of DAPS and the library are conducting a review of existing software and systems potentially appropriate for a comprehensive serials control system. The ATT study was the tool successfully used to elicit university support for library automation. The university has given its approval, and supplied funding, to proceed with the determination of available systems and with the development of a request for quotation.

\section{REFERENCES}

1. For example: University of Rochester, River Campus Libraries, Task Force on Access Systems, Report (Rochester, N.Y.: Univ. of Rochester, 1980), University of California, Berkeley, General Library, Committee on Bibliographic Control, Future of the General Library Catalogs of the University of California at Berkeley (Berkeley: Univ. of California, 1977); Pennsylvania State University Libraries, Systems Development Department, Remote Catalog Access System: General System Specifications (University Park: Pennsylvania State Univ., 1977).

2. Association of Research Libraries, Office of Management Studies, Annual Report, 1979 (Washington, D.C.: The Association, 1979).

3. International Business Machines Corporation, Application Transfer Teams: Application Description (White Plains, N.Y.: The Corporation, 1977), p.1; International Business Machines Corporation, Application Transfer Teams: Realizing Your Computing Systems' Potential (White Plains, N.Y.: The Corporation, 1977).

4. International Business Machines Corporation, Business Systems Planning: Information Systems Planning Guide (White Plains, N.Y.: The Corporation, 1975), p.49.

5. Richard W. Meyer and others, Total Integrated Library Information System: A Report on the General Design Phase (Syracuse, N.Y.: ERIC Clearinghouse on Information Resources, 1980), ED 191446.

6. Richard W. Meyer, Cooper Library: Status and Agenda. A Report on FY 1979-80 (Clemson, S.C.: Clemson Univ., 1980). 